5. Guber I, Mouvet $V$, Bergin $C$ et al (2016), Clinical Outcomes and Cataract Formation Rates in Eyes 10 Years After Posterior Phakic Lens Implantation for Myopia. JAMA Ophthalmol.

6. Dương Tấn Hùng và Nguyễn Hữu Quốc Nguyến (2013), Đánh giá kết quả phẫu thuật PHACO điêuu trị đực thủy tinh thể băng đường rạch trên giác mạc phía thái dương. Tạp chí Y học thực hành, $870(\dot{5}), 30-31$.
7. Trân Thị Phương Thu, Võ Đức Dũng, Dương Quốc Cường, et al. (2009), Đánh giá kết quả phâuu thuât phaco tai khoa Bán công - Bênh viên Mắt TP. HCM, Tạp chí Y học Thành phố Hồ Chí Minh, 13 (1).

8. Vũ Mạnh Hà (2014), Nghiên cứu phẫu thuật đục thể thuỷ tinh bằng hai phương pháp phaco và đường rach nhỏ tai tỉnh Hà Giang, Luân án Tiến sĩ, Trường Đ̇ại học Y Hà Nội.

\title{
ĐÁNH GIÁ KẾT QUẢ SỐNG THÊM SAU ĐIỀU TRI UNG THƯ ĐẠI TRÀNG GIAI ĐOẠN T4 HOẶC N1-2 BẰNG PHẪU THUÂTT CẮT TOÀN BÔ MAC TREO ĐAI TRÀNG VÀ HÓA TRI TẠI KHOA ĐIỀU TRI THEO YÊU CẦU BÊNNH VIỆN K
}

\section{TÓM TẮT}

Mục tiêu: Đánh giá kết quả sống thêm sau điều tri ung thư đai tràng giai đoan T4 hoăc N1-2 bằng phẫu thuật cắt toàn bộ mạc treo đại tràng và hóa trị tai khoa Điều trị theo yều câu Bềnh viên $K$. Đối tượng: 50 bệnh nhân được chẩn đoán ung thư đại tràng giai đoan T4 hoăc N1-2 chưa có di căn xa, đước phẫu thuật cắt toàn bộ mạc treo đại tràng và hóa trị tại khoa Điều trị theo yêu cầu Bệnh viện K trong giai đoạn 2017-2019. Kết quả: Tất cả các bệnh nhân trong nghiên cứu được mổ mở, thởi gian mổ trung bình $121,7 \pm 16,9$ phút, thời gian trung tiện trung bình là $3,5 \pm 0,5$ ngày, thời gian nằm viện trung bình là $8,7 \pm 1,1$ ngày. Chiều dài đoạn ruột trung bình là $31,2 \pm 2,4 \mathrm{~cm}$, diện cắt trên trung bình $12,8 \mathrm{~cm}$, diện cắt dưới trung bình $9,9 \mathrm{~cm}$. Số lượng hạch vét được trung bình là $30,9 \pm 19,3$ hạch, trong đó sổ lượng hạch chặng 1 trung bình là 12,3 hạch, hạch chặng 2 là 8,9 hạch, hạch chặng 3 là 5,6 hạch, hạch N2O-2A là 4,1 hạch. $50 \%$ bệnh nhân có di căn hạch với số lượng hạch di căn trung bình cho mối ca là 3,8 hạch, trong 50 bệnh nhân có $40 \%$ có di căn hạch chặng $1,28 \%$ có di căn hạch chặng 2,12\% bệnh nhân có di căn hạch chặng 3 và $6 \%$ có di căn hach nhóm N2O-2A. Khổng gặp các tai biến-biến chứng trong mổ như: tổn thương mạch máu lớn hoăc các tạng lân cân. Một bênh nhân có nhồi máu phội sau mổ đã được can thiệp lấy huyết khối, hâuu phẫu ổn đinh sau 17 ngày, 2 trường hợp bệnh nhân (4\%) có viêm phổi và rối loạn nhịp tim sau mổ (bệnh nhân có bệnh lý hô hấp hoặc tim mạch trước đó) được điều trị nội khoa ổn định. Không gặp trường hợp nào có biến chứng như chảy máu sau mổ,

\footnotetext{
${ }^{1}$ Bệnh viện $K$

${ }^{2}$ Đai hoc Y Hà Nôi

Chịu trách nhiệm chính: Bệnh viện K Email: quochoan201087@gmail.com Ngày nhận bài: 10.9.2021

Ngày phản biên khoa hoc: 27.10.2021

Ngày duyệt bài: 12.11.2021
}

Chử Quốc Hoàn1, Mai Tiến Đạt ${ }^{1}$, Dương Chí Thành ${ }^{1}$, Nguyễn Văn Hiếu ${ }^{1,2}$ rò miệng nối, hẹp miệng nối hoặc chảy máu miệng nối sau mô. $64 \%$ bệnh nhân được hóa trị phác đồ XELOX, $22 \%$ sử dụng phác đồ FOLFOX và $14 \%$ sử dụng phác đồ Capecitabine đơn thuần. Toàn bô bênh nhân đều được hoàn thiện liệu trình hóa trị, không có trường hợp nào phải ngừng điều trị do độc tính. Tất cả bệnh nhân trong nghiên cứu không gặp các biến chứng nă̆ng do hóa trị. Thời gian theo dõi trung bình đến thời điểm hiện tại là 37.1 tháng, ghi nhận 2 trường hợp tái phát chiếm $4 \%$ và 1 tứ vong chiếm $2 \%$. 1 trường hợp tái phát di căn gan và 1 trường hợp tái phát di căn phúc mạc tiểu khung.

Tư khóa: Ung thư đại tràng, Phẫu thuật cắt toàn bộ mạc treo đại tràng, CME.

\section{SUMMARY}

THE RESULTS OF COMPLETE MESOCOLIC EXCISION IN STAGE II,III COLON CANCER TREATMENT AT K HOSPITAL

Objectives: Describe the results of complete mesocolic excision in stage II,III colon cancer treatment at K hospital. Patients and methods: 50 patients was diagnosed stage II,III colon cancer at $\mathrm{K}$ hospital. Result: All patients in this study had opened surgery, the average surgery time was $121,7 \pm 16,9$ minutes, the time to first flatus was $3,5 \pm 0,5$ days, the length of hospital stay was $8,7 \pm 1,1$ days. The average specimen length was $31,2 \pm 2,4 \mathrm{~cm}$, the proximal resection margin was $12,8 \mathrm{~cm}$, the distal resection margin was $9,9 \mathrm{~cm}$. The median number of examined lymph nodes was 30,9 $\pm 19,3$, in which the number of lymph nodes in D1 was 12,3 , lymph nodes in D2 was 8,9, lymph nodes in D3 was 5,6 lymph nodes and N2O-2A lymph nodes were 4,1 nodes. Fifty percent of patients had lymph node metastases with an average of 3,8 lymph nodes per case, in which $40 \%$ had D1 lymph node metastases, $28 \%$ had D2 lymph nodes metastases, $12 \%$ of patients had D3 lymph node metastases and $6 \%$ of N2O-2A lymph node metastases. No complications such as damage to major blood vessels or adjacent organs, bleeding or 
respiratory cardiovascular complications during surgery. One patient with postoperative pulmonary infarction was intervened to remove blood clotting, postoperative stabilized after 17 days, 2 cases of patients (4\%) had pneumonia and arrhythmia after surgery (all of them had history cardiopulmonary disease) and stabilized after medical treatment. There were no complications such as postoperative bleeding, anastomotic leak or narrow . The average follow-up to the present time is 19,1 months, no cases of relapse or death have been recorded. The average time observation after surgery is 41,1 months; OS $98 \%$ and DFS $96 \%$. 1 Case (2\%) recurent peritoneal metastasis an 1 case (2\%) live metastasis.

Keyword: Colon cancer, Complete mesocolic excision, CME

\section{I. ĐĂT VẤN ĐỀ}

Ung thư đại trực tràng là bệnh lý thường gặp. Theo thống kê của Globocan 2018 công bố, tại Việt Nam hàng năm có khoảng hơn $14.000 \mathrm{ca}$ mới mắc và có khoảng hơn 7.800 ca tử vong do ung thư đại trực tràng, đứng hàng thứ 4 ở nam, thứ 5 ở nữ và thứ 5 ở cả 2 giới sau ung thư gan, phổi, dạ dày và vú. Tî lệ mới mắc khoảng $13,4 / 100.000$ dân và tỉ lệ tử vong khoảng $7 / 100.000$ dân ở cả 2 giới [1]. Trên toàn thế giới, ung thư đại tràng đứng hàng thứ 4 trong số tất cả các loại ung thư, với khoảng gần $1.100 .000 \mathrm{ca}$ mới mắc hàng năm, chiếm khoảng $6,1 \%$ tất cả các loại ung thư, trong số đó có khoảng hơn 550.000 ca tử vong hằng năm và chiếm khoảng $5.8 \%$ số ca tử cung do ung thư hàng năm [1].

Hầu hết các triệu chứng lâm sàng của ung thư đại tràng là kín đáo, khi có triệu chứng thường bệnh đã ở giai đoạn muộn. Chẩn đoán xác định bệnh chủ yếu dựa vào nội soi, sinh thiết làm giải phẫu bệnh. Chẩn đoán giai đoạn chủ yếu sử dụng CT Ścan và các biện pháp thăm dò chẩn đoán hình ảnh khác. Điều trị ung thư đai tràng giai đoạn tại chố, tại vùng, phẫu thuật đóng vai trò guan trọng nhất, hóa trị có vai trò bổ trợ sau phẫu thuật là chính, xạ trị ít có vai trò với ung thư đại tràng [2]. Phẫu thuật triệt căn ung thư đại trực tràng, đảm bảo cắt rộng khối u và vét hạch vùng rộng rãi là nguyên tắc căn bản. Tuy nhiển, mức độ vét hạch đến đâu là đủ vẫn còn là vấn đề chưa thống nhất trên toàn thế giới. Tại Nhật Bản, với những tổn thương tại chỗ đánh giá T3-T4 hoặc hạch nghi di căn, chỉ định vét hạch D3 hệ thống là quan điểm thống nhất, mang lại cho Nhật Bản kết quả sống thêm ung thư đại tràng giai đoạn II, III thuộc hàng đứng đầu trên thế giới [3]. Nghiên cứu lớn nhất của châu Âu do Hohenberg công bố năm 2009 trên cơ sở phôi thai học, mô học, giải phẫu và chuẩn hóa kĩ thuật vét hạch được tóm tắt tên gọi là cắt toàn bộ mạc treo đại tràng (Complete Mesocolic Excision -CME) thực hiệ̂n trên 1329 bệnh nhân giảm tỉ lệ tái phát tại chỗ và tăng tỉ lệ sống thêm so với các phâuu thuật của giai đoạn trước [4]. Về cơ bản vét hạch D3 của Nhật Bản gần tương tự như CME. So với các kĩ thuật vét hạch D2 hoăc trước đây, CME giảm thiểu tỉ lệ tái phát tại chỗ, tại vùng, đặc biệt là tái phát hạch tại vị trí gốc bó mạch mạc treo tràng trên hoặc mạc treo tràng dưới do nó lấy mạc treo rộng hơn, cắt đoạn ruột dài hơn và quan tâm đầy đủ hơn tới tính nguyên vẹn và bề dày mạc treo, nơi chứa các hạch bạch huyết di căn. Tại Việt Nam cũng như tại bệnh viện $\mathrm{K}$ chúng tổi gặp khá nhiêuu những trường hợp tái phát hạch gốc mạc treo như vậy, do đó quan điểm về $C M E$ mới được đưa vào thực hành trong phẫu thuật. Tuy nhiên hiện nay chưa có nhiều báo cáo nào thống kê tính an toàn về ngoại khoa cũng như các kết quả về ung thư học, sống thêm của nó. Do vậy chúng tôi tiến hành nghiên cứu này nhằm Đánh giá kết quả sống thêm sau điều trị ung thư đại tràng giai đoạn T4 hoặc N1-2 bằng phầu thuật cắt toàn bộ mạc treo đại tràng và hóa trị tại khoa Điều trị theo yêu cầu Bệnh viện K.

\section{II. ĐỐI TƯợNG VÀ PHƯƠNG PHÁP NGHIÊN CỨU}

1. Đối tượng nghiên cứu. 50 bệnh nhân bệnh nhân ung thư đại tràng giai đoạn T4-N1$2 \mathrm{M} 0$ được phẫu thuật cắt toàn bộ mạc treo đại tràng và hóa trị tại khoa Điều trị theo yêu cầu bệnh viện $\mathrm{K}$ từ tháng 1/2017 đến tháng 12 năm 2019.

Tiêu chuấn lựa chọn: Bệnh nhân được chẩn đoán xác định là ung thư biểu mô tuyển của đại tràng giai đoạn T4N1-2M0 (dựa vào đánh giá trong mổ và giải phẫu bệnh sau mổ). Được phẫu thuật cắt toàn bộ mạc treo đại tràng phải hoặc trái tùy vị trí tổn thương. Có hồ sơ lưu trữ đầy đủ và có thông tin theo dôi sau điều trị.

Tiêu chuẩn loại trừ: Các bệnh nhân mắc ung thư thứ 2. Bệnh nhân tử vong trong quá trình theo dõi do bệnh lý nội khoa cấp tính, nặng nề khác.

\section{Phương pháp nghiên cứu}

Thiết kế nghiên cứu: Nghiên cứu mô tả kết hợp hồi cứu kết hợp tiến cứu có theo dõi dọc.

Cỡ mẫu: Chọn mẫu thuận tiện. 50 bệnh nhân đủ tiêu chuẩn lựa chọn từ tháng 1/2017 đến tháng 12/2019 được đưa vào nghiên cứu.

Mô tả đặc điểm bệnh nhân: Tuổi, giới, triệu chứng lẩm sàng, giai đoạn $\mathrm{T}$, giai đoạn $\mathrm{N}$, hình thức mổ (mổ phiên hay cấp cứu). Phác đố hóa chất sử dụng 
Mô tả kết quả điêu trị: Thời gian phẫu thuật, Số ngày nằm viện, Số lượng hạch vét được, Tai biến-biến chứng trong và sau mổ.

Mô tả thời gian sống không bệnh (DFS) và thời gian sông thêm toàn bộ (OS)

\section{KẾT QUẢ NGHIÊN CỨU}

1. Một số đặc điểm của đối tượng nghiên cứu (Bảng 1). Kết quả cho thấy trong tổng số 50 bệnh nhân tham gia nghiên cứu, nam giới chiếm tỉ lệ $42 \%$, nữ giới chiếm $58 \%$. Tỉ lệ nam/nữ là $1,4 / 1$.

Tuổi trung bình của các đối tượng nghiên cứu là 55,3 tuổi, thấp nhất là 24 tuổi, cao nhất là 81 tuổi.

Số bênh nhân có bệnh lý toàn thân như tim mạch, tằng huyết áp, hô hấp, bệnh lý chuyển hóa, đái tháo đường... chiếm $24 \%$.

Có $24 \%$ bệnh nhân có biến chứng cấp cứu như tắc ruột, bán tắc ruột, lồng ruột hoặc áp-xe quanh u. Tất cả bệnh nhân trong nghiên cứu đều được mổ mở, trong đó $94 \%$ bệnh nhân mổ phiên, $6 \%$ bệnh nhân phải mổ cấp cứu vì các biến chứng nêu trên.

Trên kết quả nội soi, $88 \%$ bênh nhân u chiếm toàn bộ chu vi lòng đại tràng, $10 \%$ u chiếm nửa chu vi, $2 \%$ u chiếm $3 / 4$ chu vi lòng đại tràng.

Trên hình ảnh cắt lớp vi tính, $92 \%$ bệnh nhân có u xâm lấn tổ chức mỡ lân cận và/hoặc xâm lấn các cơ quan khác, chỉ có $8 \%$ bệnh nhân u còn khu trú ở thành đại tràng. Có $32 \%$ bệnh nhân có nghi ngờ di căn hạch trên cắt lớp vi tính.

Có $50 \%$ bệnh nhân có u thuộc nửa đại tràng phải, $48 \%$ bệnh nhân có u thuộc nửa đại tràng trái, và $2 \%$ bệnh nhân có u cả 2 bên đại tràng. Theo đó, $50 \%$ bệnh nhân được phẫu thuật cắt toàn bộ mạc treo đại tràng phải, $48 \%$ phẫu thuật cắt toàn bộ mạc treo đại tràng trái, $2 \%$ cắt toàn bộ mạc treo đại tràng 2 bên. Tất cả các bệnh nhân trong nghiên cứu đều thực hiện miệng nối, chỉ có 1 bệnh nhân (chiếm 2\%) phải làm hậu môn nhân tạo hồi tràng bảo vệ miệng nối đó là trường hợp mổ cấp cứu cắt toàn bộ đại trực tràng, tạo túi Jpouch, nối hồi tràng-ống hậu môn.

Về kết quả giải phẫu bệnh sau mổ, $68 \%$ bệnh nhân có thể mô bệnh học là ung thư biểu mô tuyến biệt hóa vừa, $24 \%$ là ung thư biểu mô tuyến nhầy, $8 \%$ là ung thư biểu mô tuyến kém biệt hóa.

Về giai đoạn sau mổ, $68 \%$ bệnh nhân ở giai đoạn T4a, 30\% ở giai đoạn T4b, 2\% ở giai đoạn T2; $52 \%$ bệnh nhân ở giai đoạn N0, 28\% bệnh nhân ở giai đoạn N1, 20\% ở giai đoạn N2. cứu

Bảng 1: Đặc điểm của đôi tượng nghiên

\begin{tabular}{|c|c|c|}
\hline Đăcc điểm & $\begin{array}{c}\text { Số bệnh } \\
\text { nhân }(n=50)\end{array}$ & $\%$ \\
\hline Giới: Nam & 21 & 42 \\
\hline Nữ & 29 & 58 \\
\hline Tuối: Trung bình & \multicolumn{2}{|l|}{$55,3 \pm 13,1$} \\
\hline Giới hạn & \multicolumn{2}{|l|}{$24-81$} \\
\hline \multicolumn{3}{|l|}{ Bệnh lý đi kèm } \\
\hline Không có & 38 & 76 \\
\hline Đái tháo đường & 3 & 6 \\
\hline Tăng huyết áp & 2 & 4 \\
\hline Rối loan nhip tim & 1 & 2 \\
\hline Bệnh lý hồ hấp & 1 & 2 \\
\hline $\begin{array}{l}\text { Đái tháo đường + } \\
\text { Tăng huyết áp }\end{array}$ & 1 & 2 \\
\hline $\begin{array}{l}\text { Tăng huyết áp+Bệnh } \\
\text { lý hô hấp }\end{array}$ & 1 & 2 \\
\hline Khác & 3 & 6 \\
\hline \multicolumn{3}{|l|}{ Biến chứng cấp cứu } \\
\hline Không có & 38 & 76 \\
\hline Tắc ruột & 4 & 8 \\
\hline Bán tắc ruôt & 5 & 10 \\
\hline Ap-xe quanh u & 1 & 2 \\
\hline Tắc ruôt+áp-xe quanh u & 1 & 2 \\
\hline Lông ruột+Bán tắc ruôtt & 1 & 2 \\
\hline \multicolumn{3}{|l|}{ Hình thức phâu thuật } \\
\hline Mố phiên & 47 & 94 \\
\hline Mố cấp cứu & 3 & 6 \\
\hline \multicolumn{3}{|l|}{ Đặc điếm u trên nội soi } \\
\hline Chiếm toàn bộ chu vi & 44 & 88 \\
\hline Chiếm $1 / 2$ chu vi & 5 & 10 \\
\hline Chiếm 3/4 chu vi & 1 & 2 \\
\hline \multicolumn{3}{|l|}{ Đăc điểm trên CT-Scan } \\
\hline $\begin{array}{l}\text { U xâm lấn lớp mõ̃ xung } \\
\text { quanh hoặc các tạng }\end{array}$ & 46 & 92 \\
\hline U giới han ở thành ĐT & 4 & 8 \\
\hline Nghi di căn hạch & 16 & 32 \\
\hline \multicolumn{3}{|l|}{ Vị trí u } \\
\hline Đại tràng phải & 25 & 50 \\
\hline $\begin{array}{c}\text { Đại tràng trái } \\
\text { Cả } 2 \text { bên đai trànq }\end{array}$ & 24 & $\begin{array}{c}48 \\
2\end{array}$ \\
\hline \multicolumn{3}{|c|}{ Mạc treo đại tràng được căt bỏ toàn bộ } \\
\hline Mạc treo đại tràng phải & 25 & 50 \\
\hline Mac treo đai tràng trái & 24 & 48 \\
\hline $\begin{array}{l}\text { Mạc treo đại tràng } \\
\text { phải+trái }\end{array}$ & 1 & 2 \\
\hline \multicolumn{3}{|c|}{ Đoạn đại tràng cắt bỏ } \\
\hline Cắt nưa đại tràng phải & 22 & 44 \\
\hline Cắt đoan đai tràng sigma & 20 & 40 \\
\hline Cắt nưa đai tràng trái & 4 & 8 \\
\hline Cắt toàn bộ đại tràng & 3 & 6 \\
\hline $\begin{array}{c}\text { Cắt toàn bộ đại trực } \\
\text { tràng }\end{array}$ & 1 & 2 \\
\hline \multicolumn{3}{|c|}{ Giải phâu bệnh sau mố } \\
\hline Carcinoma tuyến biệt & 34 & 68 \\
\hline
\end{tabular}




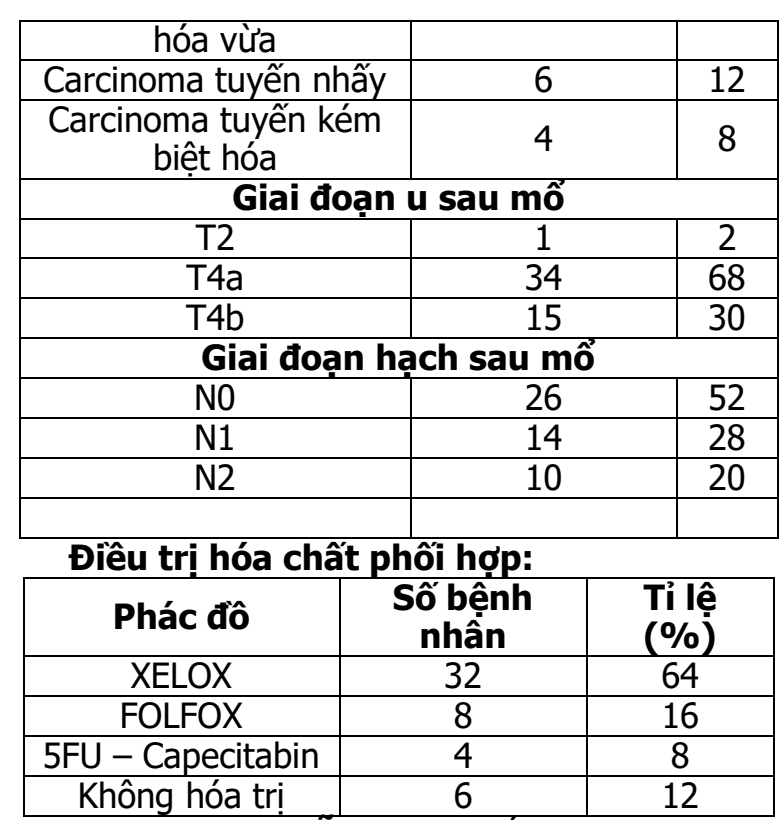

2. Kết quả phầu thuật cắt toàn bộ mạc treo đại tràng. Thời gian phẫu thuật trung bình là $121,7 \pm 16,9$ phút. Thời gian trung tiện trung bình là $3,5 \pm 0,5$ ngày, thời gian nằm viện trung bình là $8,7 \pm 1,1$ ngày.

Chiều dài đoạn ruột cắt trung bình là $31,2 \pm 20,4 \mathrm{~cm}$ (ngắn nhất $16 \mathrm{~cm}$, dài nhất $120 \mathrm{~cm}$ ). Diên cắt trên trung bình $12,8 \mathrm{~cm}$, diện cắt dưới trung bình $9,9 \mathrm{~cm}$.

Số lượng hạch vét được trung bình là 30,9 19,3 hạch, Trong đó số lượng hạch chặng 1 trung bình là 12,3 hạch, hạch chặng 2 trung bình là 8,9 hạch, hạch chặng 3 trung bình là 5,6 hạch và $\mathrm{N} 2 \mathrm{O}-2 \mathrm{~A}$ là 4,1 hạch. Có $50 \%$ bệnh nhân có di căn hach với số lượng hạch di căn trung bình cho mỗi ca là 3,8 hạch. Trong nhóm bệnh nhân có di căn hạch, $40 \%$ bệnh nhân có di căn hạch chặng $1,28 \%$ có di căn hạch chă̆ng $2,12 \%$ có di căn hạch chăng 3 và $6 \%$ có di căn hạch nhóm N2O-2A. Tất cả những trường hợp di căn nhóm 20-2A đều có di căn hạch chặng 2 và/hoặc chặng 3 . Trong số $12 \%$ trường hợp có di căn hạch chặng 3 , có $10 \%$ trường hợp di căn hạch các chặng trước đó và $2 \%$ di căn hạch nhẩy cóc (khổng có di căn các chặng hạch khác).

Trong tất cả các trường hợp trong nghiên cứu, chúng tôi không gặp bất kì trường hợp nào có các tai biến, biến chứng trong mổ như: chảy máu trong mổ, tổn thương mạch máu lớn hoặc các tạng lân cận, mất máu hay các biến chứng tim mạch hô hấp trong mổ. Có 1 trường hợp bệnh nhân xuất hiện nhồi máu phổi sau mổ đã được can thiệp mạch cấp cứu lấy huyết khối thành công và hậu phẫu ổn định sau 17 ngày, 2 trường hợp có viêm phổi và rối loạn nhịp tim sau mổ (trên cơ địa có các bệnh lý tim mạch, hô hấp trước đó) được điều trị nội khoa ổn định.

Đồng thời, chúng tôi cũng không gặp trường hợp nào xuất hiện các biến chứng như chảy máu sau mổ, rò miệng nối, hẹp miệng nối hay chảy máu miệng nối.

Thời gian theo dõi trung bình cho tới tháng $8 / 2021$ là 41,1 tháng, trong quá trình theo dõi chúng tôi ghi nhận 2 trường hợp nào tái phát chiếm tỉ lệ $4 \%$, trong đó 1 trường hợp di căn nhân phúc mạc tiểu khung 1 trường hợp di căn gan và 1 trường hợp tử vong sau khi xuất hiện tái phát nhưng không đáp ứng với hóa trị.

\section{BÀN LUÂN}

Kết quả nghiên cứu cho thấy, thời gian phẫu thuật trung bình là 121,7 phút, ít hơn so với nghiên cứu của Kang (2014) với thời gian phẫu thuật trung bình là 192 phút [5]. Sự khác biệt này là do nghiên cứu của Kang, phấu thuật cắt toàn bộ mạc treo đại tràng được tiến hành qua nội soi và chỉ thực hiện trên nhóm bệnh nhân ung thư đại tràng phải. Thời gian trung tiện trung bình là 3,5 ngày, thời gian nằm viện trung bình là 8,7 ngày. Thời gian nằm viện trung bình của các bệnh nhân trong nghiên cứu của chúng tôi dài hớn so với trong nghiên cứu của Kang (2014) (5 ngày) có lẽ do $100 \%$ các bệnh nhân của chúng tôi đều được tiến hành mổ mở, trong khi toàn bộ các bệnh nhân trong nghiên cứu của Kang đều được phẫu thuật nội soi [5]. Chiều dài đoạn ruột cắt bỏ trung bình là $31,2 \mathrm{~cm}$, diện cắt trên trung bình là $12,8 \mathrm{~cm}$, diện cắt dưới trung bình là $9,9 \mathrm{~cm}$. So với nghiên cứu của Kang và cộng sự, chiều dài đoạn ruột cắt bỏ của chúng tồi dài hơn, có lẽ do nghiên cứu của chúng tôi thực hiện trên tất cả các bệnh nhân mắc ung thư đại tràng (ở mọi vị trí), trong đó có 3 bệnh nhân (chiếm $6 \%$ ) cắt toàn bộ đại tràng, 1 bệnh nhân (chiếm $2 \%$ ) cắt toàn bộ đại trực tràng. Diện cắt trên và dưới trong nghiên cứu cũng tương tự như kết quả nghiên cứu của Kang và cộng sự [5].

Số lượng hạch vét được trung bình trong nghiên cứu của chúng tôi là 30,9 hạch, kết quả này tương tự trong nghiên cứu của Hohenberger (2009) với số lượng hạch vét được trung bình là 32 hạch [4].

Trong nghiên cứu của chúng tôi, không có trường hợp nào gặp tai biến, biến chứng trong mổ. Có 1 trường hợp bệnh nhân xuất hiện nhồi máu phổi sau mổ đã được can thiệp kịp thời lấy huyết khối thành công, 2 trường hợp bệnh nhân có viêm phổi và rối loạn nhịp sau mổ đều được 
điều trị nội khoa ổn định. Đồng thời trong nghiên cứu cũng không gặp các biến chứng sau mổ như chảy máu, rò miệng nối, hẹp miệng nối.... Các kết quả này đều thấp hơn so với nghiên cứu của Hohenberger (2009) và nghiên cứu của Kang (2014) với tỉ lệ biến chứng chung lần lượt là $19,7 \%$ và $4,6 \%[4],[5]$.

Về hóa trị, chúng tôi sử dụng các phác đồ kinh điển cho bổ trợ như FOLFOX, XELOX hay Capecitabin đơn thuần, đây là các phác đồ được sử dụng phối hợp tương tự như các tác giả chẩu Âu, châu Á khác. Tất cả bệnh nhân đều được hoàn thành liệu trình điều trị và không có trường hợp nào xuất hiện các độc tính nặng dẫn tới phải dừng điều trị hoặc chuyển phác đồ.

Nghiên cứu của chúng tôi cho thấy tỉ lệ sống thêm không bệnh sau thời gian theo dõi trung bình 41,1 tháng là $96 \%$ tương tự như các kết quả của tác giả Hohenberg là $95,1 \%$ và của các tác giả Nhật Bản là 92,4\% sau thời gian theo dõi 5 năm[6].

\section{KẾT LUÂN}

Nghiên cứu của chúng tôi, hiện tại tuy chỉ thực hiện trên 50 bệnh nhân, nhưng bước đâu đã cho thấy tính khả thi, an toàn và mang lại kết quả sống thêm tốt của phẫu thuật cắt toàn bộ mạc treo đại tràng và hóa trị bổ trợ trong điều trị ung thư đại tràng giai đoạn T4 hoặc N1-2 chưa di căn xa.

Tỉ lệ sống thêm không bệnh sau thời gian theo dối trung bình 41,1 tháng là $96 \%$ và sống thêm toàn bộ là $98 \%$. Tỉ lệ tái phát chiếm $4 \%$ trong đó $2 \%$ tái phát di căn gan và $2 \%$ tái phát di căn phúc mạc tiểu khung.

\section{TÀI LIÊU THAM KHẢO}

1. Bray F., Ferlay J., Soerjomataram I. và cộng sư. (2018). Global cancer statistics 2018: GLOBOCAN estimates of incidence and mortality worldwide for 36 cancers in 185 countries. CA Cancer J Clin, 68(6), 394-424.

2. Watanabe T., Muro K., Ajioka Y. và cộng sứ. (2018). Japanese Society for Cancer of the Colon and Rectum (JSCCR) guidelines 2016 for the treatment of colorectal cancer. Int J Clin Oncol, 23(1), 1-34.

3. Hohenberger W., Weber K., Matzel K. và cộng sự. (2009). Standardized surgery for colonic cancer: complete mesocolic excision and central ligation - technical notes and outcome. Colorectal Dis, 11(4), 354-364.

4. Kang J., Kim I., Kang S.I. và cộng sự. (2014). Laparoscopic right hemicolectomy with complete mesocolic excision. Surg Endosc, 28(9), 2747-2751.

5. Yojiro Hashiguchi, Kei Muro, Yutaka Saito3, KenichiSugihara33. Japanese Society for Cancer of the Colon and Rectum. Japanese Society for Cancer of the Colon and Rectum (JSCCR) guidelines 2019 for the treatment of colorectal cancer. 29 May 2019.. International Journal of Clinical Oncology Vol.:(0123456789).1 3.

\section{NGHIÊN CỨU ĐĂC ĐIỂM LÂM SÀNG, CÂN LÂM SÀNG CỦA BÊ̂NH NHÂN UNG THƯ HA HỌNG CÓ KHỐI UNG THƯ NGUYÊN PHÁT THỨ HAI}

\section{TÓM TẮT}

Mục tiêu: Nghiên cứu đặc điểm lâm sàng, cận lâm sàng của bệnh nhân ung thư hạ họng có khối ung thư nguyên phát thứ hai. Phương pháp nghiên cứu: Mô tả căt ngang. Đối tượng: 41 bệnh nhân ung thư hạ họng có khối ung thư nguyên phát thứ hai tại Bệnh viện Tai Mũi Họng Trung Ương. Kết quả: Tỷ lệ xuất hiện khối ung thư nguyên phát thứ hai là $4,7 \%$. 41 bênh nhân ung thư ha hong có khối ung thư nguyển phát thứ hai toàn bộ là nam giới, tuổi trung bình $57,34 \pm 6,95$, hầu hết có tiền sử sử dụng thuốc lá và rượu nhiều năm. Triệu chứng lâm sàng hay gặp

${ }^{1}$ Trường Đại học Y Hà Nội

${ }^{2}$ Bênh viên Tai Mũi Hong Trung Ương

Chịu trách nhiệm chính: Tô Thị Trang Anh

Email: tranganh929@gmail.com

Ngày nhận bài: 10.9.2021

Ngày phản biên khoa hoc: 29.10.2021

Ngày duyệt bài: 11.11.2021

\section{Tô Thị Trang Anh"1, Tống Xuân Thắng ${ }^{1,2}$}

nhất là rối loạn nuốt (97,6\%): nuốt vướng 80,5\%, nuốt đau $53,7 \%$, nuốt nghẹn $14,6 \%$, khàn tiếng $34,1 \%$, bệnh nhân gâyy sút cân rõ $24,4 \%$. Hay gặp nhất khối u hạ họng ở giai đoạn T2 chiếm 46,3\% và giai đoạn T3 chiếm $36,6 \%, 12,2 \%$ ở giai đoạn T1. Trên lâm sàng, có 90,2\% bệnh nhân không nghi ngờ hach di căn, có 7,3\% bệnh nhân ở giai đoan N1 và chỉ có 1 bệnh nhân ở giai đoạn N2. 97,6\% bệnh nhân có khối ung thư nguyên phát thứ hai ở thực quản, chỉ có 1 bệnh nhân khối ung thư nguyên phát thứ hai ở họng miêng. $1 / 3$ giữa thực quản là vị trí hay găp tổn thương ung thư nhất ở 56,8\%. 100\% bệnh nhân ung thư biểu mô vảy, đa phần đô mô học III. Kết luân: Bệnh nhân ung thư hạ họng nói riêng và ung thư biểu mô vùng đâu cổ có nguy cớ có khối ung thư nguyên phát thứ hai, làm tăng tiên lượng xấu, ảnh hưởng tới phương án điêu trị và khả năng sống sót của bênh nhân. Khố ung thư nguyên phát thứ hai thường nẳm ở đường hô hấp tiêu hóa trên và phổi. Triêu chứng lâm sàng đa dạng thường bị che lấp bởi triệu chứng tại khối ung thư nguyên phát. Trong chiến lược quản lý bệnh nhân 